p1147 Cot-death
culprit: Is a newly
discovered virus
responsible for
SIDS?

\title{
Scientists seeking HIV in all the wrong places
}

HIV annihilates immune cells in the gut rather than the blood, a surprising discovery that, experts say, may require a total rethink of strategies to design HIV drugs and vaccines.

HIV infects and destroys a subset of disease-fighting cells called $\mathrm{CD}^{+} \mathrm{T}$ cells. Doctors routinely measure levels of these cells in the blood to monitor virus progression and to evaluate the effectiveness of experimental drugs and vaccines. Based on these measurements, it is widely assumed that HIV does not wipe out large quantities of these cells until months or years into the infection.

Two papers published in September shatter that assumption by showing that the virus demolishes $\mathrm{T}$ cells in the gut within weeks of
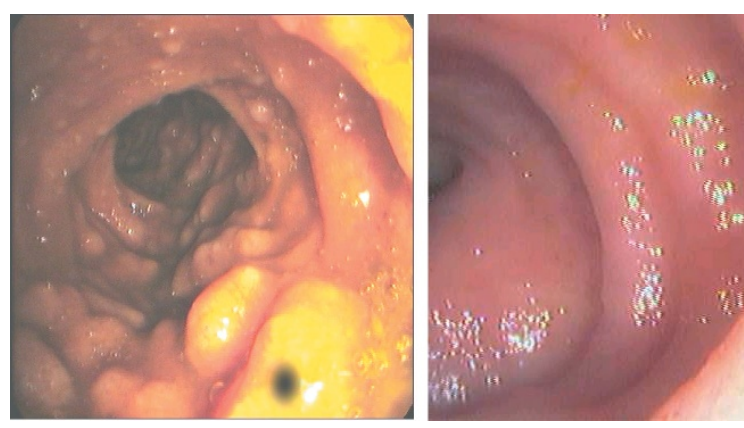

Bumps of lymphoid tissue seen in a normal gut (L) are wiped out by HIV (R). infection (J. Exp. Med. 200, 749-759; 2004 and J. Exp. Med. 200, 761-770; 2004). "It's an enormously important observation," says microbiologist Ronald Desrosiers, who studies monkey models of HIV at Harvard Medical School.

The discovery suggests that measuring $\mathrm{T}$ cells in the blood will not accurately portray the damage being wreaked by the virus elsewhere in the body, or whether therapies are taking effect. Indeed, one of the two teams showed that the T-cell population in the gut does not recover in chronically infected patients taking antiretroviral therapy, even if their blood counts improve. Because gut biopsies are so invasive, however, they are unlikely to become a normal part of disease monitoring.

Desrosiers says the finding should also refocus efforts to find a vaccine. At present, vaccines are designed to boost T-cell levels in the blood. But a vaccine that specifically protects the gut from infection, perhaps by being swallowed rather than injected, might be more effective. "It may be we've been barking up the wrong tree," says Desrosiers. He and others have already begun working on experimental forms of such vaccines.

The idea that HIV might attack T cells in the gut stemmed from a 1998 study showing that HIV's simian counterpart, SIV, does the same in the gastrointestinal tract of monkeys (Science $280,427-431$; 1998). But it was difficult to repeat the work in newly infected patients reluctant to undergo uncomfortable gut biopsies.

Part of the explanation for the damage in the gut may be that a large proportion of $\mathrm{T}$ cells there display CCR5, a receptor that HIV uses to infect cells. The gut also harbors the vast majority of the body's T cells to fight off pathogens in food; the blood, by contrast, carries only $2-5 \%$. "That explains why the depletion is so dramatic," says Danny Douek, a researcher at the US National Institute of Allergy and Infectious Diseases, who led one of the studies.

Besides its implications for vaccines, the studies back the case for developing drugs that specifically protect the gut. They also argue for using antiretroviral therapy in high-risk individuals as a preventative treatment to block the virus from establishing infection early on. "Personally, I feel this should be pursued with extreme vigor," says Desrosiers.

Helen Pearson, New York

\section{Spain breaks financial pact with pharmaceutical industry}

The Spanish pharmaceutical industry is up in arms against a new law that requires companies to give the government money based on their drug sales. The government estimates that the scheme will generate $€ 200$ million per year, half of which will be set aside to fund biomedical research in the country.

Relationships between Farmaindustriawhich represents more than 300 drug companies - and the ministry soured in 1999 when the ministry lowered the caps it imposes on drug prices by $6 \%$. Spain's spending on drugs is among the highest in Europe.

In 2001, Farmaindustria agreed to 'voluntarily' deliver funds, provided that the annual spending increased by $6.5-9.5 \%$ each year. In return, the government promised not to lower the caps again (Nature 414, 138; 2001). With money earned from this scheme, the ministry's research agency was able to fund both the national cancer and cardiovascular centers and nationwide networks of excellence (Nat.Med.9,378; 2003).

"The previous government was interested in seeing the spending increasing instead of lowering since this way it would get more money for research," health minister Elena Salgado said when announcing the new measures on 28 September. But the ministry now wants companies to be legally required to contribute to research, she said. "We no longer want to be the inmates of industry."

According to the new law, companies will be obliged to provide funds proportional to their annual drug sales. The government grants employers a $60 \%$ discount rate on prescription drug prices, and has to 'return' this money to the companies every year.
Companies are to benefit from special discounts to encourage research and development, but the following day, Farmaindustria said it "fully rejects the measure." The law will dampen companies' investment in research because "[money for] private projects will be transferred to public ones," says the group's spokesman Julián Zabala.

"It's risky and not sensible" that public research would depend on industry funds, adds Mariano Esteban of the Madrid-based National Biotechnology Center.

Pere Puigdoménech, director of the Barcelona-based Institute of Molecular Biology, says the new law could be good for Spanish researchers. But he warns that "adding more pressure" to drug companies might mean that smaller companies will close. Xavier Bosch, Barcelona 